\title{
Soret and Dufour Effects on Magneto-hydrodynamics Newtonian Fluid Flow beyond a Stretching/Shrinking Sheet
}

\author{
Shahanaz Parvin ${ }^{1}$, Siti Suzilliana Putri Mohamed Isa ${ }^{1,2, *}$, Norihan Md. Arifin ${ }^{1,3}$, Fadzilah Md Ali ${ }^{1,3}$ \\ Institute for Mathematical Research, Universiti Putra Malaysia, 43400 UPM Serdang, Selangor Darul Ehsan, Malaysia \\ Centre of Foundation Studies for Agricultural Science, Universiti Putra Malaysia, 43400 UPM Serdang, Selangor Darul Ehsan, Malaysia \\ 3 Department of Mathematics, Faculty of Science, Universiti Putra Malaysia, 43400 UPM Serdang, Selangor Darul Ehsan, Malaysia
}

\section{ARTICLE INFO}

\section{Article history:}

Received 21 June 2020

Received in revised form 20 August 2020

Accepted 25 August 2020

Available online 31 August 2020

\section{Keywords:}

Magnetohydrodynamics; stretching surface; suction; Soret number; Dufour number

\section{ABSTRACT}

The boundary layer flow and heat transfer of an incompressible fluid beyond a stretching/shrinking sheet has numerous industrial applications, such as wire and plastic films drawing, paper and glass fiber production and hot rolling. The product of these industrial applications depend on the heat transfer rate at the stretching/shrinking sheet. Therefore, the numerical reports of magneto hydrodynamics Newtonian fluid flow, which is induced by a stretching/shrinking sheet is developed. This model is subjected to the impact of mass and heat transfer, known as Soret and Dufour parameters, respectively. The velocity, temperature and concentration of the Newtonian fluid are assumed to have exponential function forms. The governing equations are in the form of partial differential equations (PDE), and contain the features of momentum, energy and concentrations. Subsequently, nonsimilarity transformation is applied on the governing basic equations. As a result, these PDE will converted to the ordinary differential equations (ODE). These ODE are then solved numerically using the shooting method. The numerical results of skin friction coefficient, local Nusselt number and local Sherwood number are obtained for several sets of values of the parameters. In addition, the profiles of velocity, temperature and concentration are presented due to the effect of controlling parameters: Soret and Dufour parameters. The characteristics of the flow, heat and mass transfer on the Newtonian fluid are described in detail in this study. As a result, it is found that velocity, concentration and skin friction coefficient increase with the increasing Soret and Dufour parameters.

\section{Introduction}

In the process in fluid flow induced by coupled heat and mass transfer, Soret and Dufour effects must not be neglected. The boundary layer fluid flow with the occurrence of coupled heat and mass transfer have significant contributions in heat insulation, compact heat exchangers, paper

\footnotetext{
* Corresponding author.

E-mail address: ctsuzilliana@upm.edu.my (Siti Suzilliana Putri Mohamed Isa)
} 
production, drying technology and catalytic reactors [1]. The mass transfer created by the temperature gradient is called the Soret effect (thermo-diffusion), whilst the heat transfer generated by the concentration gradient is called the Dufour effects (diffusion-thermo). From experimental reports, the diffusion of matter and heat due to Soret and Dufour effects become effective when the gradients of these two elements are very large. When the gradient of the temperature and the concentration are large, the coupled interaction between Soret and Dufour effects are sufficiently great [2]. As a result, the boundary layer fluid flow in the presence of heat and mass transfer considering Soret and Dufour effects are being explored due to the stretching or shrinking surface. The published reports are taking into account the various function of stretching/shrinking velocity, temperature and concentration distributions. Therefore, the linear function Soret-Dufour fluid flow model are being explored due to the additional impacts and various types of fluid [3-8]. The impact of magnetic field on the Soret-Dufour fluid flow model are developed by Bég et al., [3] and Hayat et al., [4]. The Soret Dufour fluid flow model on the following fluid: Casson [4], Oldroyd-B [5, 7], hyperbolic tangent [6], and Carreau-Yasuda [8] are reported respectively. The previous reports [3-8] show different characteristics on the aspects of flow, heat and mass transfer due to the various types of fluid model. However, the velocity of the stretching/shrinking layer may not essentially be linear. The magnetohydrodynamics fluid flow beyond a nonlinear stretching/shrinking sheet are studied by Rashidi et al., [9] and Pal et al., [10]. Besides, the fluid flow model that applied the velocity, temperature and concentration functions in exponential forms were solved theoretically [11-17]. Two-dimensional Soret-Dufour exponential model [11-15] and three-dimensional fluid flow exponential function model [16-17] are formed on the stretching or shrinking sheet. The various numerical techniques are applied to determine the numerical results from governing equations (which form the equations of momentum, energy and concentration). The methods are namely as Keller-box method $[11,13]$, Homotopy analysis method [16-17], shooting method $[12,15]$ and bvp4c program under Matlab software [14].

Recently, the problem of convection in the fluid bounded/beyond the shape other than flat stretching/shrinking sheet with the addition of Soret-Dufour parameters has been solved. The mixed convection magnetohydrodynamics fluid flow over a rotating vertical cone is studied by Chamkha and Rashad [18]. Ali et al., [19] solved the model problem of Soret-Dufour fluid flow with the occurrence of natural convection in porous trapezoidal enclosures. Meanwhile, Hayat et al., [20] reported the incompressible couple stress fluid in an inclined asymmetric channel, subjected to the effect of magnetic field and chemical reaction. The second grade fluid flow along a cylindrical coordinate system due to the effect of thermal radiation is analysed by Shojaei et al., [21].

This paper applies the problem formulation developed by Srinivasacharya and RamReddy [11], and the fluid model is extended to the permeable shrinking case. The exponential functions of velocity, temperature and concentration is applied in the Soret-Dufour fluid model [11-14]. In addition, previous finding solved the case of mixed convection opposing flow [14]. Besides, this paper changes the previous model [14] to the assisting convective fluid flow. The main purpose of this paper is to explore the Soret and Dufour effects on magneto-hydrodynamics Newtonian fluid flow beyond a stretching/shrinking sheet. The numerical and graphical findings are obtained by using shooting method. Skin friction coefficient, local Nusselt number and local Sherwood number are tabulated for different values of Soret and Dufour number. The graphical results of velocity, temperature and concentration profiles for various values of Soret and Dufour number are explained in details. The main findings are mentioned in the conclusions. 


\section{Methodology}

The two-dimensional of an incompressible, viscous and electrically conducting Newtonian fluid bounded by a stretching/shrinking sheet is considered to develop the mathematical formulation. The exponential variation of the stretching/shrinking sheet is expressed as $u_{w}(x)=\lambda U_{0} \exp (x / L)$. The stretching parameter is denoted as $\lambda>0$, whereas shrinking parameter is measured when $\lambda<0$. The stretching/shrinking sheet is placed on the $x$-axis and the uniform magnetic field $B_{0}$ is applied on the $y$-axis. Therefore, the model problem is expressed by the governing equations Eq. (1-4). These governing equations are continuity, momentum, energy and concentrations. In addition, these governing equations are under the boundary conditions (as shown in Eq. (5)). The governing equations, together with the boundary conditions are shown, as below:

$\frac{\partial u}{\partial x}+\frac{\partial v}{\partial y}=0$

$\frac{\partial u}{\partial t}+u \frac{\partial u}{\partial x}+v \frac{\partial u}{\partial y}=v \frac{\partial^{2} u}{\partial y^{2}}+g \beta_{T}\left(T-T_{\infty}\right)+g \beta_{C}\left(C-C_{\infty}\right)+\frac{\sigma B_{0}^{2}}{\rho} u$

$u \frac{\partial T}{\partial x}+v \frac{\partial T}{\partial y}=\alpha \frac{\partial^{2} T}{\partial y^{2}}+\frac{D K_{T}}{C_{S} C_{P}} \frac{\partial^{2} C}{\partial y^{2}}$

$u \frac{\partial C}{\partial x}+v \frac{\partial C}{\partial y}=D \frac{\partial^{2} C}{\partial y^{2}}+\frac{D K_{T}}{T_{m}} \frac{\partial^{2} T}{\partial y^{2}}$

$u=u_{w}(x)=\lambda U_{0} \exp (x / L), \quad v=v_{w}(x), \quad T_{w}(x)=T_{\infty}+T_{0} \exp (x / 2 L)$,

$C_{w}(x)=C_{\infty}+C_{0} \exp (x / 2 L), \quad$ at $y=0$

$u \rightarrow 0, T \rightarrow T_{\infty}, \quad C \rightarrow C_{\infty} \quad$ at $y \rightarrow \infty$

where $u$ and $v$ are the components of velocity in the $x$ and $y$-directions, $v=\frac{\mu}{\rho}$ is the kinematic viscosity, $\mu$ denotes the viscosity, $\rho$ is the fluid density, $g$ is the gravitational acceleration, $\beta_{T}$ is the coefficient of thermal expansion, $\beta_{C}$ is the coefficient of solutal expansions, $T$ is the temperature of the fluid, $C$ is concentration of the fluid, $\sigma$ is the electrical conductivity, $\alpha$ is the thermal diffusivity, $D$ is the solutal diffusivity of the medium, $K_{T}$ is the thermal diffusion ratio, $C_{S}$ is the concentration susceptibility, $C_{P}$ is the specific heat at constant pressure and $T_{m}$ is the mean fluid temperature and the wall mass suction velocity is represented by $v_{w}(x)<0$. The term $\exp (x / 2 L)$ in temperature $T_{w}$ and concentration distribution $C_{w}$ are used [11-14] in this problem for the case of two-dimensional flow exponential variation with the presence of Soret-Dufour effects and when concentration equation included in governing equations. The assumption of temperature and concentration functions are to make sure the numerical results will satisfy final boundary condition after substituting similarity variables (Eq. (6)).

The purpose of using Eq. (6) is to convert the governing equations (in the form of partial differential equations PDE) into ordinary differential equations ODE. The list of ODE is presented by Eqs. (7-9). Besides, the new boundary conditions, Eq. (10) will be obtained due to the assistance of similarity variables. Finally, the new ordinary differential equations and boundary conditions are obtained as below: 
$\theta(\eta)=\frac{T-T_{\infty}}{T_{w}-T_{\infty}}, \quad \varphi(\eta)=\frac{C-C_{\infty}}{C_{w}-C_{\infty}}, \quad \eta=y\left(\frac{U_{0}}{2 v L}\right)^{1 / 2} \exp (x / 2 L)$,

$u=U_{0} \exp (x / L) f^{\prime}(\eta)$

$v=-\left(\frac{v U_{0}}{2 L}\right)^{1 / 2} \exp (x / 2 L)\left[f(\eta)+\eta f^{\prime}(\eta)\right]$

$f^{\prime \prime \prime}+f f^{\prime \prime}-2\left(f^{\prime}\right)^{2}+2 R i\left[\exp \left(\frac{-3 X}{2}\right)\right](\theta+N \varphi)-2 H[\exp (-X)] f^{\prime}=0$

$\frac{1}{P r} \theta^{\prime \prime}+f \theta^{\prime}-f^{\prime} \theta+D b \varphi^{\prime \prime}=0$

$\frac{1}{S c} \varphi^{\prime \prime}+f \varphi^{\prime}-f^{\prime} \varphi+\operatorname{Sr} \theta^{\prime \prime}=0$

$f^{\prime}(\eta)=\lambda, \quad f(\eta)=S, \theta(\eta)=1, \quad \varphi(\eta)=1 \quad$ at $\eta=0$

$f^{\prime}(\eta) \rightarrow 0, \quad \theta(\eta) \rightarrow 0, \quad \varphi(\eta) \rightarrow 0$

as $\eta \rightarrow \infty$

where prime indicates the differentiation with respect to $\eta$, where $\eta$ is the boundary layer thickness. The parameters involved in this problem are formulated in Table 1. From this table, negative $R i$ indicates opposing flow, otherwise it indicates the case of aiding flow. Besides, the profiles of velocity, temperature and concentration are denoted by $f^{\prime}(\eta), \theta(\eta)$ and $\varphi(\eta)$.

\section{Table 1}

List of parameters and profiles

\begin{tabular}{ll}
\hline Parameter/Profiles Name & Formula/Denotation \\
\hline Mixed convection parameter & $R i=G r / R e^{2}$ \\
Magnetic field parameter & $H=2 \sigma L B_{0}^{2} / \rho U_{0}$ \\
Thermal Grashof number & $G r=g \beta_{T}\left(T_{0}-T_{\infty}\right) L^{3} / v^{2}$ \\
Reynolds number & $R e=U_{0} L / v$ \\
Buoyancy ratio & $N=\beta_{C}\left(C_{0}-C_{\infty}\right) / \beta_{T}\left(T_{0}-T_{\infty}\right)$ \\
Dimensionless coordinate along the plate & $X=x / L$ \\
parameter, where $L$ is the length of the sheet & $P r=v / \alpha$ \\
Prandtl number & $S c=v / D$ \\
Schmidt number & $S r=\left[D K_{T}\left(T_{0}-T_{\infty}\right)\right] /\left[T_{m} v\left(C_{0}-C_{\infty}\right)\right]$ \\
Soret number & $D b=\left[D K_{T}\left(C_{0}-C_{\infty}\right)\right] /\left[C_{S} C_{P} v\left(T_{0}-T_{\infty}\right)\right]$ \\
Dufour number & $S=\left(v_{w}(x) / \exp (x / 2 L) \times \sqrt{2 L / v U_{0}}\right)>0$ \\
Suction parameter &
\end{tabular}

The physical parameters of skin friction coefficient $C_{f}$, local Nusselt number $N u_{x}$ and local Sherwood number $S h_{x}$ are presented as follow:

$C_{f}=\left(\frac{\mu}{\rho U_{0}^{2}}\right)\left(\frac{\partial u}{\partial y}\right), \quad N u_{x}=\left(\frac{L}{T_{w}-T_{\infty}}\right)\left(-\frac{\partial T}{\partial y}\right)_{y=0}, \quad S h_{x}=\left(\frac{L}{C_{w}-C_{\infty}}\right)\left(-\frac{\partial C}{\partial y}\right)_{y=0}$

Substituting Eq. (6) into Eq. (11), then we get 


$$
\begin{aligned}
& C_{f} \sqrt{2 R e_{x}} \exp \left(\frac{-3 X}{2}\right)=f^{\prime \prime}(0), \quad N u_{x} \sqrt{2 / R e_{x}} \exp \left(\frac{-X}{2}\right)=-\theta^{\prime}(0), \\
& S h_{x} \sqrt{2 / R e_{x}} \exp \left(\frac{-X}{2}\right)=-\varphi^{\prime}(0)
\end{aligned}
$$

The numerical solutions are obtained by applying shooting method, which developed in Maple software. The shooting technique gives the solutions for the boundary value problems by changing Eqs. (7-10) into an initial value problem. The fourth-order of Runge-Kutta integration scheme is applied to solve the initial value problem. We set:

$$
\begin{aligned}
& f^{\prime}=f p \\
& f p^{\prime}=f p p, \\
& f p p^{\prime}=-\left[f f p p-2(f p)^{2}+2 R i\left\{\exp \left(-\frac{3 X}{2}\right)\right\}(\theta+N \varphi)-2 H\{\exp (-X)\} f p\right] \\
& \theta^{\prime}=\theta p, \\
& \theta p^{\prime}=-\operatorname{Pr}\left(f \theta p-f p \theta+D b \varphi p^{\prime}\right) \\
& \varphi^{\prime}=\varphi p, \\
& \varphi p^{\prime}=-S c\left(f \varphi p-f p \varphi+\operatorname{Sr} \theta p^{\prime}\right) \\
& f p(\eta)=\lambda, \quad f(\eta)=S, \theta(\eta)=1, \quad \varphi(\eta)=1 \quad \text { at } \eta=0 \\
& f p(\eta) \rightarrow 0, \theta(\eta) \rightarrow 0, \quad \varphi(\eta) \rightarrow 0
\end{aligned}
$$

The guess value for $f^{\prime \prime}(0),-\theta^{\prime}(0)$ and $-\varphi^{\prime}(0)$ have to be predicted in this method, together with the guess value of highest boundary layer thickness $\eta_{\infty}$. The final numerical results are obtained when the most appropriate value of $\eta_{\infty}$ is selected and until two consecutive values of $f^{\prime \prime}(0),-\theta^{\prime}(0)$ and $-\varphi^{\prime}(0)$ vary significantly by a specified values.

\section{Results and Discussion}

Dual numerical solutions are obtained in this article in the graphs of velocity, temperature and concentration profiles. Dual solutions also appeared in the calculations of skin friction coefficient, local Nusselt number and local Sherwood number. However, only one solution is linearly stable and physically realizable. Stable solution shows the satisfaction of boundary conditions (Eq. (10)) without or with the minimal existence of minimum and maximum peak. This solution can be determined, by performing stability analysis [22]. In this paper, the stability analysis is not calculated due to the limitations of page number. Therefore, the stable solution is labelled as the first solution and it is selected due to its pattern which follows continuously the boundary conditions. Besides, another solution is labelled as second solution and it is unstable. As a conclusion, second solution is not physically reliable in the actual state of fluid. 
Numerical graphics have been performed for the velocity profile $f^{\prime}(\eta)$, temperature profile $\theta(\eta)$ and concentration profile $\varphi(\eta)$ for various values of physical parameters as Soret Srand Dufour parameters $D b$. First and second solutions are drawn by solid and dashed line, respectively. In the present study, the following values are fixed for the entire MatLab programme unless otherwise mentioned: $\quad S=2.5, H=S c=P r=R i=1, \quad N=0.5, X=0.1, S r=2$, and $\quad D b=0.03$. Moreover, the largest of fluid thickness $\eta=8$ is constantly used for numerical computations.

The validation of our numerical results obtained from Maple software is performed, by presenting the comparison with the pioneer investigators $[12,23]$ in the case of exponentially stretching sheet $\lambda>0$. Magyari and Keller [23] were the original pioneers who studied the flow and thermal boundary layers on a stretching sheet that has temperature and velocity in exponential forms. Besides, Srinivasacharya and RamReddy [12] were the pioneers who explored the model of SoretDufour fluid flow, beyond an exponentially stretching sheet. This comparison is reported for the numerical values of wall-temperature gradient $-\theta^{\prime}(0)$ for various values of Prandtl number $P r$ and stretching parameter $\lambda$, as shown in Table 2. As a conclusion, the present values of $-\theta^{\prime}(0)$ are in good agreement with those reported by the previous investigators. Therefore, the good comparison proves that our shooting method is applicable to use for providing subsequent findings in this paper.

Table 2

The comparison on wall-temperature gradient $\theta^{\prime}(0)$ for various values of $S r$ and $D b$ when $S=H=R i=S c=N=X=S r=D b=0$

\begin{tabular}{lllll}
\hline$\lambda$ & $P r$ & $\begin{array}{l}\text { Magyari and } \\
\text { Keller [23] }\end{array}$ & $\begin{array}{l}\text { Srinivasacharya } \\
\text { and RamReddy [12] }\end{array}$ & Present \\
\hline \multirow{3}{*}{1} & 1 & -0.95478 & -0.95478 & -0.95478 \\
& 3 & -1.86908 & -1.86908 & -1.86907 \\
& 5 & -2.50014 & -2.50015 & -2.50013 \\
\hline \multirow{3}{*}{0.9} & 1 & & & 0.90579 \\
& 3 & - & - & 1.77316 \\
& 5 & & & 0.07692 \\
\hline & 1 & & - & -0.85399 \\
0.8 & 3 & - & & -1.67175 \\
& 5 & & & -2.23618 \\
\hline
\end{tabular}

Figure 1 shows the influence of Soret number $\mathrm{Sr}$ on velocity (a), temperature (b) and concentration (c) respectively in the flow induced by stretching sheet $\lambda=1$. The first solution shows the uniform decrement of instantaneous velocity due to the distance from the stretching sheet $\eta$, until the velocity reaches constant zero value. Therefore, it is proved that the zero velocity at the point far from stretching sheet denoted that there is no fluid movement at this point. Velocity profiles for second solution decreases for small $\eta$ and reach minimum point, then it increases until it achieve zero value. The rate of velocity in the first solution increases as the value of Soret number $\mathrm{Sr}$ increases. On the other hand, the velocity pattern of second solution due to the impact of $\mathrm{Sr}$ shows the same result as the first solution for the small value of $\eta$. However, the values of velocity for the second solution influenced by the same parameter is decrease for large value of $\eta$. Furthermore, the first solution of temperature distribution decreases with the increasing value of $S$ for the small $\eta$. However, the effect of $S r$ is to enhance the rate of $\theta(\eta)$ for the first solution, at the large $\eta$. In addition, the effect of $S r$ is to reduce the temperature profile of the second solution. The concentration profile of the fluid for the first solution has an increment due to impact of $S r$ at a very small value of $\eta$. As the value of $S r$ and $\eta$ increase, the value of first solution concentration remain constant. In second solution, the impact of $\mathrm{Sr}$ is significant near the stretching sheet, and this point shows the augmentation of concentration. 
Figure 2 shows the effect of Dufour number $D b$ on velocity (a), temperature (b) and concentration (c) profiles respectively in the flow induced by stretching sheet $\lambda=1$. In this figure, as the value of Dufour number increases, the line graph of first solution is clearly shows that the values of velocity as well as the boundary layer thickness increase. However, for second solution, it is observed that the result is same as the first solution for the small value of $\eta$. For the thicker fluid, the value of velocity for second solution is decrease. Furthermore, Figure 2 shows the first solution of temperature distribution increases with the increasing value of $D b$. However, the second solution of temperature distribution decreases for larger $\eta$. The concentration profile of the fluid for first solution has a significant increase for a thinner fluid. However, the reversible pattern is observed for a thicker fluid and influenced by the same parameter. This means that the concentration profile increases for the first solution due to the impact of $D b$ for the very small and very large $\eta$. In second solution, the concentration profile is raise up as the value of Dufour number is enhanced.
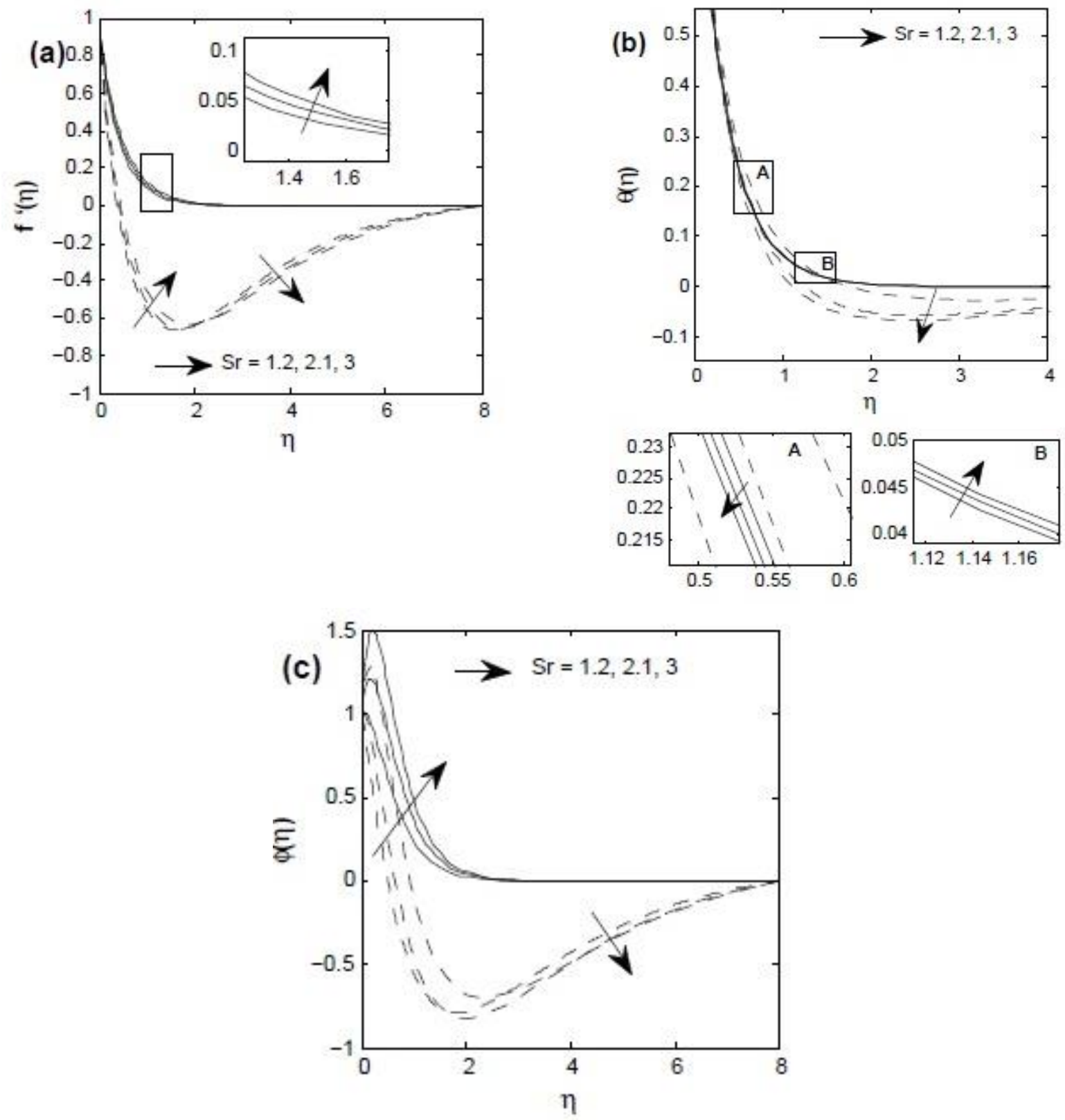

Fig. 1. The effect of $S r$ on velocity (a), temperature (b) and concentration (c) profiles for the stretching case 

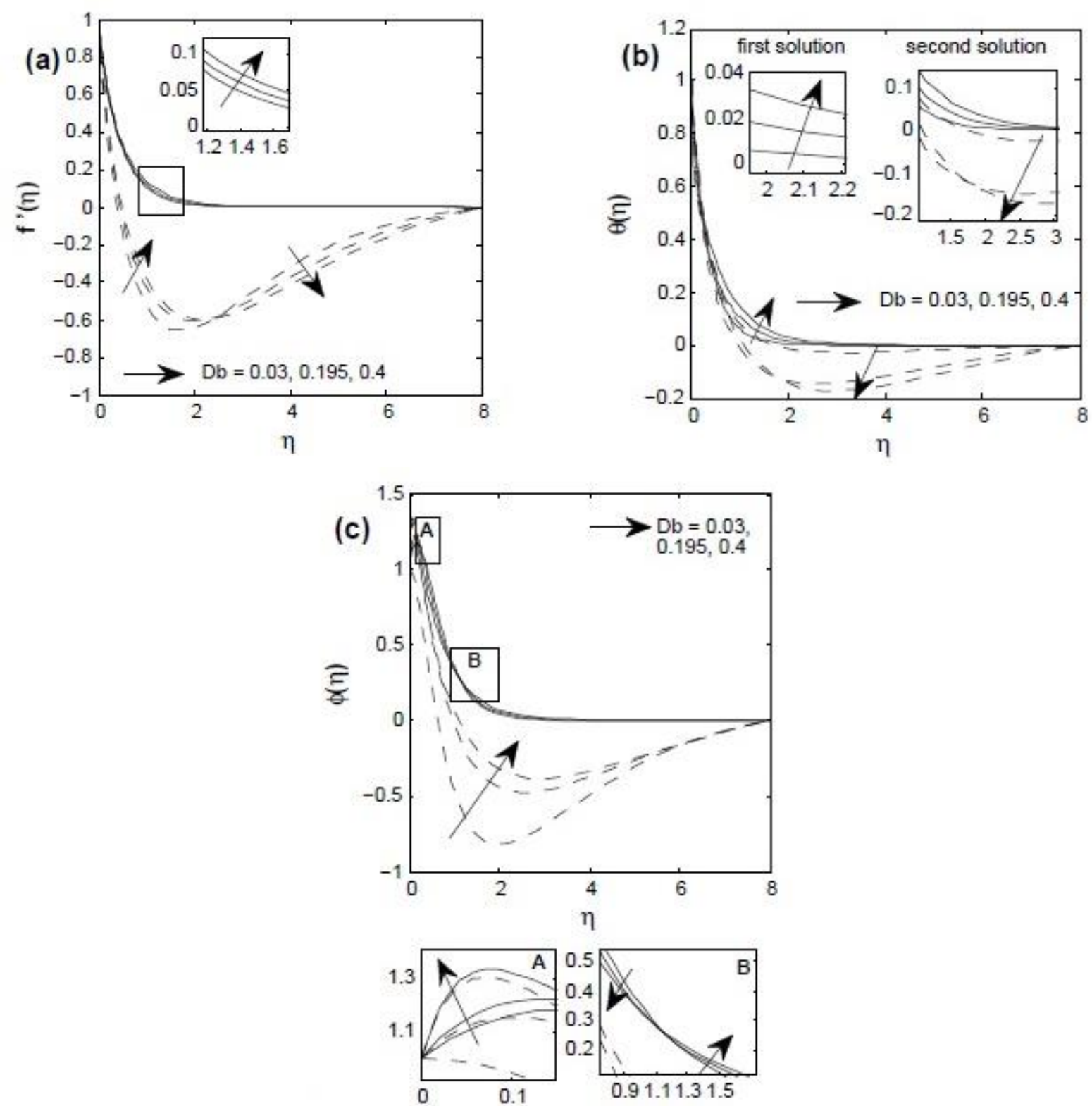

Fig. 2. The effect of $D b$ on velocity (a), temperature (b) and concentration (c) profiles for the stretching case

Figure 3 shows the impact of Soret number $\mathrm{Sr}$ on velocity (a), temperature (b) and concentration (c) respectively in the flow due to the shrinking case $\lambda=-1$. It is observed that the velocity profile for the first solutions increases due to the addition of $\mathrm{Sr}$. Besides, the parameter $\mathrm{Sr}$ reduces the variation of velocity of the second solution. This figure shows that the first solution of temperature profile decreases as the value of $S r$ increases. This decrement can be seen at the small $\eta$ for the first solution. The increment of temperature profile for the thicker fluid is observed, by the impact of $\mathrm{Sr}$ and for the first solution. The temperature rate is increased for the second solution, due to the parameter $\mathrm{Sr}$. Moreover, this graphic representations show the existence of maximum peak of concentration profile at small $\eta$. The first solution concentration reaches certain maximum point and then it continuously reduces, and finally the concentration vanishes. In addition, it is found that the increase of $\mathrm{Sr}$ causes an increment of the concentration profile variation for the first solution. The existence of minimum peak can be observed for the second solution concentration variation. 
When the Soret parameter is incremented, the concentration profile for the second solution decreases.
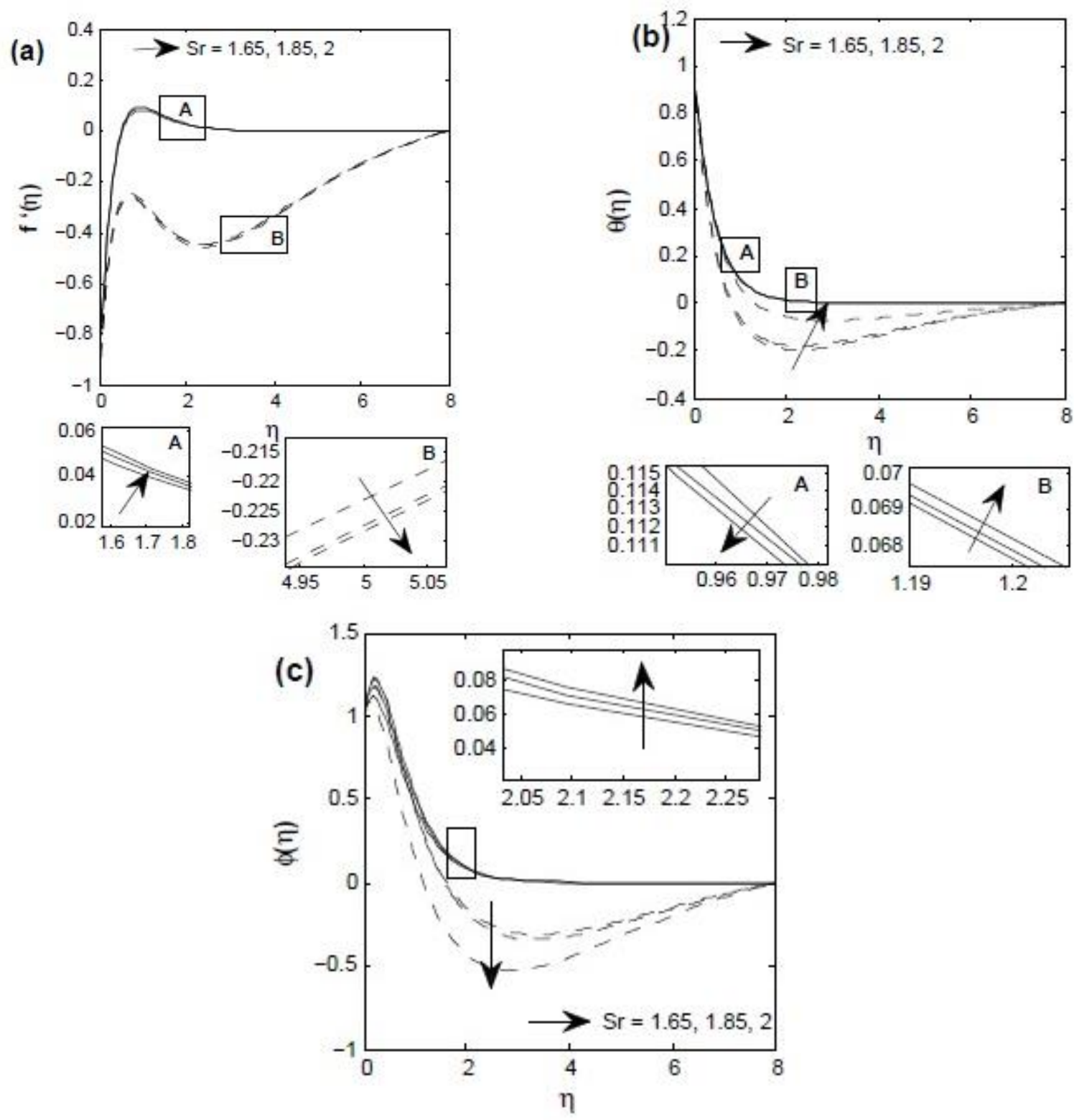

Fig. 3. The effect of $S r$ on velocity (a), temperature (b) and concentration (c) profiles for the shrinking case

The impact of Dufour number $D b$ on velocity (a), temperature (b) and concentration profiles (c) are depicted respectively in Figure 4 for the shrinking case $\lambda=-1$. The effectiveness of $D b$ on second solution velocity variation showing that the velocity is increased when the fluid is thin and reduced at the thicker fluid. On the other hand, the velocity profile increases for the first solution. From Figure 4, the temperature profile for the first solution is increased with the increasing value of $\mathrm{Db}$. On the other hand, the decrement of temperature profile can be seen for the second solution. Figure 4 shows that the concentration distribution increases with the increasing Dufour parameter $D b$, for the first solution. This pattern can be seen at the distance close and far from the shrinking sheet. The impact of $D b$ is significant on second solution concentration profile, showing that the concentration in enhanced due to the same parameter. 

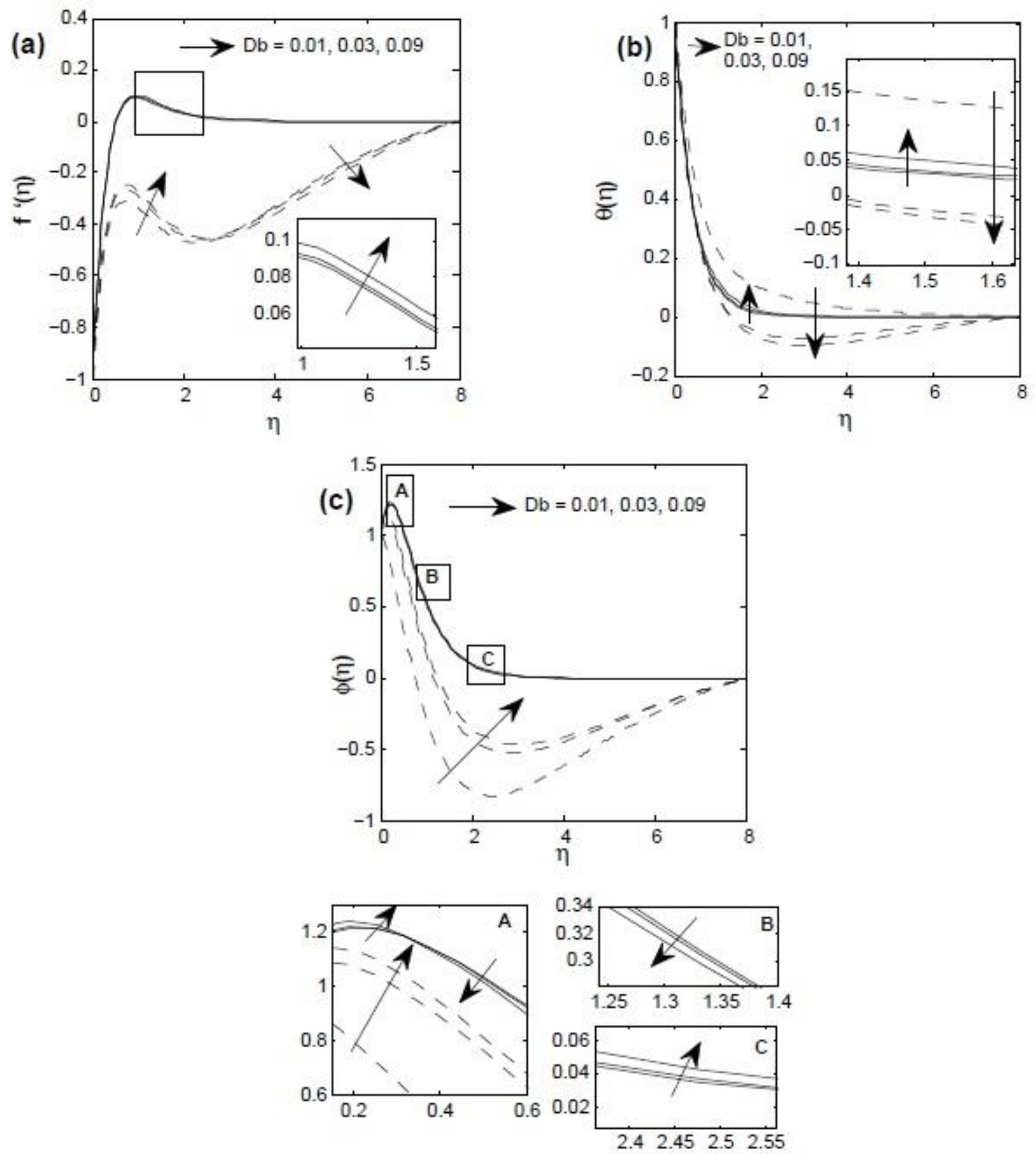

Fig. 4. The effect of $D b$ on velocity (a), temperature (b) and concentration (c) profiles for the shrinking case

From all the figures, they can be seen that $S r$ and $D b$ have opposite characteristics on the temperature and concentration profiles. These characteristics are described on the first solution only, since this solution is stable and physically reliable. Mass transfer from the lower to the higher rate of concentration due to temperature gradient is recognized by Soret effect. Therefore, concentration is enhanced due to the increment of Soret number (Figure 1 and 3). Concentration gradient induces heat transfer from the lower to the higher temperature profile, which labeled by Dufour effect. As a result, Figure 2 and 4 shows that large $D b$ increases temperature and thickness of thermal layer at the distance close to the stretching/shrinking sheet. 
The distribution of skin friction coefficient $C_{f} \sqrt{2 R e_{x}} \exp \left(\frac{-3 X}{2}\right)$, local Nusselt number $N u_{x} \sqrt{2 / R e_{x}} \exp \left(\frac{-X}{2}\right)$ and local Sherwood number $S h_{x} \sqrt{2 / R e_{x}} \exp \left(\frac{-X}{2}\right)$ for various values of Soret and Dufour parameters and for stretching and shrinking cases are presented in Tables 3 and 4, respectively. Table 3 shows that both $C_{f} \sqrt{2 R e_{x}} \exp \left(\frac{-3 X}{2}\right)$ and $N u_{x} \sqrt{2 / R e_{x}} \exp \left(\frac{-X}{2}\right)$ are increasing for the first solution when the values of Soret and Dufour number rise, while $S h_{x} \sqrt{2 / R e_{x}} \exp \left(\frac{-X}{2}\right)$ is decreasing due to the same parameters and for the both solutions. From Table 4, it is clear that there are increasing values for $C_{f} \sqrt{2 R e_{x}} \exp \left(\frac{-3 X}{2}\right)$ and decreasing values for $S h_{x} \sqrt{2 / R e_{x}} \exp \left(\frac{-X}{2}\right)$ as the values of Soret and Dufour number is increased for both solutions. The local Nusselt number rate increases with the augmentation of $S r$ and $D b$ for the second solution and for the shrinking case, as shown in Table 4.

\section{Table 3}

The values of skin friction coefficient, local Nusselt number and local Sherwood number due to the effect of parameters $S r$ and $D b$ for the stretching case $(\lambda=1)$

\begin{tabular}{|c|c|c|c|c|c|c|c|}
\hline \multirow[t]{2}{*}{ Parameters } & \multirow[t]{2}{*}{ Values } & \multicolumn{2}{|c|}{$C_{f} \sqrt{2 R e_{x}} \exp \left(\frac{-3 X}{2}\right)$} & \multicolumn{2}{|c|}{$N u_{x} \sqrt{2 / R e_{x}} \exp \left(\frac{-X}{2}\right)$} & \multicolumn{2}{|c|}{$S h_{x} \sqrt{2 / R e_{x}} \exp \left(\frac{-X}{2}\right)$} \\
\hline & & $\begin{array}{l}\text { First } \\
\text { solution }\end{array}$ & $\begin{array}{l}\text { Second } \\
\text { solution }\end{array}$ & $\begin{array}{l}\text { First } \\
\text { solution }\end{array}$ & $\begin{array}{l}\text { Second } \\
\text { solution }\end{array}$ & $\begin{array}{l}\text { First } \\
\text { solution }\end{array}$ & $\begin{array}{l}\text { Second } \\
\text { solution }\end{array}$ \\
\hline \multirow{3}{*}{$S r$} & 1.3 & -2.58789 & -4.07059 & 2.89582 & 2.75452 & -0.63794 & 1.67585 \\
\hline & 2.1 & -2.46788 & -3.88627 & 2.97252 & 2.74340 & -2.92478 & -0.36510 \\
\hline & 3.0 & -2.33589 & -3.59395 & 3.06222 & 3.05994 & -5.63404 & -4.17941 \\
\hline \multirow[t]{3}{*}{$D b$} & 0.030 & -2.48273 & -3.90949 & 2.96279 & 2.73702 & -2.63288 & -0.08310 \\
\hline & 0.195 & -2.45895 & -3.62822 & 3.68698 & 3.84603 & -4.06988 & -3.37517 \\
\hline & 0.400 & -2.43029 & -3.50409 & 7.89786 & 8.07367 & -12.47691 & -12.04820 \\
\hline
\end{tabular}

Table 4

The values of skin friction coefficient, local Nusselt number and local Sherwood number due to the effect of parameters $S r$ and $D b$ for the shrinking case $(\lambda=-1)$

\begin{tabular}{llllllll}
\hline Parameters & Values & \multicolumn{2}{c}{$C_{f} \sqrt{2 R e_{x}} \exp \left(\frac{-3 X}{2}\right)$} & \multicolumn{2}{c}{$N u_{x} \sqrt{2 / R e_{x}} \exp \left(\frac{-X}{2}\right)$} & \multicolumn{2}{c}{$S h_{x} \sqrt{2 / R e_{x}} \exp \left(\frac{-X}{2}\right)$} \\
\cline { 3 - 8 } & & First & Second & First & Second & First & Second \\
& & solution & solution & solution & solution & solution & solution \\
\hline \multirow{2}{*}{$S r$} & 0.5 & 2.57800 & 3.79400 & 2.37344 & 2.16731 & 1.73509 & 1.07689 \\
& 1.0 & 2.77988 & 3.91108 & 2.29725 & 2.21874 & 0.76163 & -0.06763 \\
& 1.9 & 3.19806 & 4.11190 & 2.68274 & 2.31146 & -2.73267 & -2.22744 \\
\hline$D b$ & 0.03 & 3.11325 & 4.13354 & 2.30703 & 2.32182 & -1.51473 & -2.47570 \\
& 0.09 & 3.17325 & 4.14262 & 2.54168 & 2.51275 & -2.15800 & -2.85551 \\
& 0.16 & 3.94684 & 4.15310 & 2.75938 & 2.82199 & -3.62853 & -3.47250 \\
\hline
\end{tabular}

\section{Conclusions}

The effect of increasing Soret number (and a simultaneous decrease in Dufour number) and Dufour number (and a simultaneous decrease in Soret number) on magnetohydrodynamics Newtonian fluid flow beyond a stretching/shrinking sheet are investigated. In this section, only the first solution is described because it is physically possible in actual fluid flow, heat and mass transfer. As a result, the following conclusions have been made:

i. The velocity and concentration profiles for both cases (stretching and shrinking sheet) are increased by increasing the Soret and Dufour numbers. The increment functions of velocity and concentration are significant at the distance close to the stretching sheet. At the same 
distance, the temperature field is increased when Dufour number increases, and shows reverse pattern due to the impact of Soret number.

ii. Skin-friction coefficient increases whereas local Sherwood number decreases with the increasing $\mathrm{Sr}$ and $\mathrm{Db}$ for both stretching and shrinking sheets. Local Nusselt number increases for stretching sheet due to the both parameters, whereas it will be increased with the increasing $D b$.

\section{Acknowledgement}

This research was funded by a grant from Universiti Putra Malaysia (Project code: GPIPM/2018/9596900).

\section{References:}

[1] Bhattacharyya, Krishnendu, G. C. Layek, and G. S. Seth. "Soret and Dufour effects on convective heat and mass transfer in stagnation-point flow towards a shrinking surface." Physica Scripta 89, no. 9 (2014): 095203. https://doi.org/10.1088/0031-8949/89/9/095203

[2] Pal, Dulal, and Hiranmoy Mondal. "Influence of Soret and Dufour on MHD buoyancy-driven heat and mass transfer over a stretching sheet in porous media with temperature-dependent viscosity." Nuclear Engineering and Design 256 (2013): 350-357.

https://doi.org/10.1016/i.nucengdes.2012.08.015

[3] Bég, O. A., A. Y. Bakier, and V. R. Prasad. "Numerical study of free convection magnetohydrodynamic heat and mass transfer from a stretching surface to a saturated porous medium with Soret and Dufour effects." Computational Materials Science 46, no. 1 (2009): 57-65

https://doi.org/10.1016/i.commatsci.2009.02.004

[4] Hayat, T., S. A. Shehzad, and A. Alsaedi. "Soret and Dufour effects on magnetohydrodynamic (MHD) flow of Casson fluid." Applied Mathematics and Mechanics 33, no. 10 (2012): 1301-1312.

https://doi.org/10.1007/s10483-012-1623-6

[5] Ashraf, M. Bilal, T. Hayat, A. Alsaedi, and S. A. Shehzad. "Soret and Dufour effects on the mixed convection flow of an Oldroyd-B fluid with convective boundary conditions." Results in Physics 6 (2016): 917-924. https://doi.org/10.1016/j.rinp.2016.11.009

[6] Hayat, Tasawar, Muhammad ljaz Khan, Muhammad Waqas, and Ahmed Alsaedi. "Stagnation point flow of hyperbolic tangent fluid with Soret-Dufour effects." Results in physics 7 (2017): 2711-2717.

https://doi.org/10.1016/j.rinp.2017.07.014

[7] Farooq, Asma, Ramzan Ali, and Ali Cemal Benim. "Soret and Dufour effects on three dimensional Oldroyd-B fluid." Physica A: Statistical Mechanics and its Applications 503 (2018): 345-354.

https://doi.org/10.1016/j.physa.2018.02.204

[8] Khan, M. ljaz, Tasawar Hayat, Sidra Afzal, M. Imran Khan, and Ahmed Alsaedi. "Theoretical and numerical investigation of Carreau-Yasuda fluid flow subject to Soret and Dufour effects." Computer methods and programs in biomedicine 186 (2020): 105145. https://doi.org/10.1016/j.cmpb.2019.105145

[9] Rashidi, Mohammad Mehdi, Mohamed Ali, Behnam Rostami, Peyman Rostami, and Gong-Nan Xie. "Heat and mass transfer for MHD viscoelastic fluid flow over a vertical stretching sheet with considering soret and dufour effects." Mathematical Problems in Engineering 2015 (2015). https://doi.org/10.1155/2015/861065

[10] Pal, Dulal, Gopinath Mandal, and Kuppalapalle Vajravalu. "Soret and Dufour effects on MHD convective-radiative heat and mass transfer of nanofluids over a vertical non-linear stretching/shrinking sheet." Applied Mathematics and Computation 287 (2016): 184-200. https://doi.org/10.1016/j.amc.2016.04.037

[11] Srinivasacharya, D., and Ch. RamReddy. "Soret and Dufour effects on mixed convection from an exponentially stretching surface." International Journal of Nonlinear Science 12, no. 1 (2011): 60-68.

[12] Sreenivasulu, P., and N. Bhaskar Reddy. "Soret and Dufour Effects on Boundary Layer Flow past an Exponential Stretching Sheet with Thermal Radiation and Viscous Dissipation." Appl. Math. 51 (2012): 10809-10816.

[13] Sharada, Kankanala. "MHD mixed convection flow of a Casson fluid over an exponentially stretching surface with the effects of soret, dufour, thermal radiation and chemical reaction." World Journal of Mechanics 5, no. 09 (2015): 165-177. 
https://doi.org/10.4236/wjm.2015.59017

[14] Isa, Siti Suzilliana Putri Mohamed, Norihan Md Arifin, and Umer Farooq. "Effect of Soret and Dufour numbers on double diffusive mixed convection boundary layer flow induced by a shrinking sheet." In Journal of Physics: Conference Series, vol. 1298, no. 1, p. 012024. IOP Publishing, 2019. https://doi.org/10.1088/1742-6596/1298/1/012024

[15] Dero, Sumera, Azizah Mohd Rohni, and Azizan Saaban. "MHD micropolar nanofluid flow over an exponentially stretching/shrinking surface: Triple solutions." Journal of Advanced Research in Fluid Mechanics and Thermal Sciences 56, no. 2 (2019): 165-174.

[16] Hayat, T., T. Muhammad, S. A. Shehzad, and A. Alsaedi. "Soret and Dufour effects in three-dimensional flow over an exponentially stretching surface with porous medium, chemical reaction and heat source/sink." International Journal of Numerical Methods for Heat \& Fluid Flow 25, no. 4 (2015): 762-781. https://doi.org/10.1108/HFF-05-2014-0137

[17] Hayat, Tasawar, Ikram Ullah, Taseer Muhammad, and Ahmed Alsaedi. "Radiative three-dimensional flow with Soret and Dufour effects." International Journal of Mechanical Sciences 133 (2017): 829-837. https://doi.org/10.1016/i.ijmecsci.2017.09.015

[18] Chamkha, Ali J., and A. M. Rashad. "Unsteady heat and mass transfer by MHD mixed convection flow from a rotating vertical cone with chemical reaction and Soret and Dufour effects." The Canadian Journal of Chemical Engineering 92, no. 4 (2014): 758-767. https://doi.org/10.1002/cice.21894

[19] Al-Mudhaf, A. F., A.M. Rashad, Sameh E. Ahmed, A. J. Chamkha, and S.M.M. EL-Kabeir. "Soret and Dufour effects on unsteady double diffusive natural convection in porous trapezoidal enclosures." International Journal of Mechanical Sciences 140, (2018): 172-178. https://doi.org/10.1016/i.ijmecsci.2018.02.049

[20] Hayat, Tasawar, Sabia Asghar, Anum Tanveer, and Ahmed Alsaedi. "Chemical reaction in peristaltic motion of MHD couple stress fluid in channel with Soret and Dufour effects." Results in physics 10 (2018): 69-80. https://doi.org/10.1016/i.rinp.2018.04.040

[21] Shojaei, Ahmadreza, A. Jafarian Amiri, S. Saedi Ardahaie, Kh Hosseinzadeh, and D. D. Ganji. "Hydrothermal analysis of Non-Newtonian second grade fluid flow on radiative stretching cylinder with Soret and Dufour effects." Case Studies in Thermal Engineering 13 (2019): 100384. https://doi.org/10.1016/i.csite.2018.100384

[22] Ishak, Anuar. "Flow and heat transfer over a shrinking sheet: A stability analysis." International Journal of Mechanical, Aerospace, Industrial and Mechatronics Engineering 8, no. 5 (2014): 905-9.

[23] Magyari, E., and B. Keller. "Heat and mass transfer in the boundary layers on an exponentially stretching continuous surface." Journal of Physics D: Applied Physics 32, no. 5 (1999): 577. https://doi.org/10.1088/0022-3727/32/5/012 